\title{
'QUANDO UMA TRANS É MORTA, OUTRAS MIL SE LEVANTAM!': TRANSNECROPOLÍTICA E TRANSRESISTÊNCIA NO BRASIL ${ }^{1}$
}

\author{
Joseli Maria SILVA² \\ Marcio Jose ORNAT3 \\ Vinícius CABRAL4 \\ Débora LEE
}

\begin{abstract}
RESUMO
A pesquisa constrói a compreensão de como os espaços de morte são representados por travestis e transexuais brasileiras. Vários estudos indicaram problemas estruturais relacionados às mortes de pessoas que compõe este grupo social. Para a construção deste texto foram realizadas doze entrevistas com travestis e transexuais. A estimulação do discurso sobre o espaço e a morte foi realizada através do uso de notícias sobre esse assunto, veiculadas em jornais on-line. As entrevistas foram analisadas por meio da análise de conteúdo que possibilitou construir e reconhecer os significados das representações sociais criadas pelo grupo sobre a relação entre espaço e morte. As representações sociais estabelecidas pelo grupo trazem a ideia de aumento da violência, culpando o grupo por sua própria condição de marginalidade e, além disso, traz o território da prostituição como uma possibilidade para a vida e simultaneamente como risco de morte.
\end{abstract}

Palavras-chave: Space. Morte. Representações sociais. Travestis. Transsexual Feminina.

\section{'WHEN A TRANS IS KILLED, ANOTHER THOUSAND RISE!' TRANSNECROPOLITICS AND RESISTANCE IN BRAZIL}

\begin{abstract}
The research comprises how the spaces of death are represented by Brazilians travestis and female transsexuals. Several studies have indicated the structural problems linked with the deaths of people who takes part in this group. For the construction of this text were conducted twelve interviews with travestis and female transsexuals. The stimulation of discourse about space and death was

\footnotetext{
${ }^{1}$ Texto apresentado em palestra realizada no II Congresso Brasileiro de Organização do Espaço (II CBOE) e XIV Seminário do Programa de Pós-Graduação, realizado na cidade de Rio Claro/SP, entre os dias 24 a 28 de março de 2019, intitulado "Soberania e Ciência no século XXI: a decolonialidade do saber como novo paradigma geográfico?".

2 Pesquisadora Senior e Docente do Programa de Pós-Graduação em Geografia da Universidade Estadual de Ponta Grossa (UEPG). E-mail: joseli.genero@gmail.com

3 Professor Associado no Departamento de Geociências e no Programa de Pós-Graduação em Geografia da Universidade Estadual de Ponta Grossa (UEPG). E-mail: geogenero@gmail.com 4 Licenciado em Geografia pela Universidade Estadual de Ponta Grossa (UEPG). Membro do Grupo de Estudos Territoriais (GETE). E-mail: vinicius.cabral.1991@gmail.com
} 
accomplished through the use of news on this topic, conveyed in newspapers on line. The interviews were analyzed using content analysis which was enable to build and recognize the meanings of social representations created by the group on the relationship between space and death. Social representations established by the group bring the idea of increasing violence, blaming the group for its own marginality condition and moreover, brings the territory of prostitution as a possibility for life and simultaneously as well as risk of death.

Keywords: Space. Death. Social Representations. Travestis. Female Transexual.

\section{‘CUANDO UNA TRANS ES ASESINADA, OTRAS MIL SE LEVANTAN!': TRANSNECROPOLÍTICA Y TRANSRESISTENCIA EN BRASIL}

\section{RESUMEN}

La investigación construye una comprensión de cómo los espacios de muerte son representados por travestis y mujeres transexuales brasileñas. Varios estudios han indicado problemas estructurales relacionados con la muerte de personas en este grupo social. Para la construcción de este texto, se realizaron doce entrevistas con travestis y mujeres transexuales. La estimulación del discurso sobre el espacio y la muerte se logró mediante el uso de noticias sobre este tema, publicadas en periódicos online. Las entrevistas fueron analizadas a través de análisis de contenido que permitió construir y reconocer los significados de las representaciones sociales creadas por el grupo sobre la relación entre el espacio y la muerte. Las representaciones sociales establecidas por el grupo traen la idea de una mayor violencia, culpando al grupo por su propia condición de marginalidad $\mathrm{y}$, además, traen el territorio de la prostitución como una posibilidad de vida y simultáneamente como un riesgo de muerte.

Palabras clave: Espacio. Muerte. Representaciones sociales. Travestis. Transexual femenina.

\section{INTRODUÇÃ̃}

Nos encontros de formação política e militância trans no Brasil, travestis e transexuais5, com os punhos cerrados erguidos para o alto, repetem várias vezes a sentença que intitula o capítulo 'quando uma trans é morta, outras mil

\footnotetext{
5 Mulheres trans e travestis são pessoas designadas no nascimento como pertencentes ao sexo masculino, mas se identificam com o gênero feminino. No Brasil, a identidade transexual é recente, havendo vários tensionamentos entre pessoas que se autoidentificam como travestis e mulheres trans no movimento LGBTI. Ser travesti, implica, manter o pênis e fazer uso dele. Mas, acima de tudo, ser travesti é uma identidade política de resistência, como evidenciado por Silva e Ornat (2016).
} 
se levantam'. Após essas palavras de ordem são citados os nomes de vítimas de assassinatos conformando uma espécie de ritual de luto para expressar publicamente a dor sentida pela perda de vidas que se foram de forma trágica. O ritual evidencia a revolta e a disposição de luta contra a violência sofrida cotidianamente na transfóbica sociedade brasileira.

As travestis e transexuais femininas constituem um grupo de alta vulnerabilidade à morte violenta e prematura no Brasil. Apesar de não haver estudos sistemáticos sobre a expectativa de vida das travestis e transexuais femininas, Antunes (2013) afirma que a expectativa de vida do grupo seja de 35 anos de idade, enquanto a da população brasileira é de 74,9 anos (IBGE, 2013). A Organização Não Governamental Transgender Europe, que monitora os assassinatos de pessoas trans no mundo, afirma que o Brasil é o país que mais reporta crimes de ódio (BALZER, HUTTA, ADRIÁN, HYLDAL E STRYKER, 2012). A Organização Não Governamental brasileira Grupo Gay da Bahia (2014) comunicou em seu relatório anual que em 2014 houve um total de 326 assassinatos de pessoas da comunidade LGBTI no Brasil, sendo que, 134 deles foram de travestis. A Associação Nacional de Travestis e Transexuais (ANTRA) contabilizou 117 mortes de pessoas trans no território brasileiro entre os meses de janeiro a agosto de $2017^{6}$.

As mortes violentas que vitimizam travestis e transexuais no Brasil são resultantes de complexas relações e práticas de violência material e simbólica que atravessam de forma simultânea as estruturas sociais, econômicas e culturais e atingem os corpos que transgridem a heteronormatividade compulsória (BUTLER, 1993). As travestis e transexuais são cotidianamente expostas à morte em um processo contínuo de desumanização de suas vidas precárias, conforme Butler (2004).

Embora a morte seja uma ocorrência cotidiana e universal, as experiências de morte são mediadas pelas interseções do corpo, cultura, sociedade e estado (MADDRELL E SIDAWAY, 2010). Sendo assim, a morte do

6 Mapa dos casos de assassinatos de Travestis e Transexuais no território brasileiro no ano de 2017 contabilizados pela Associação Nacional de Travestis e Transexuais (ANTRA). Disponível em https://www.google.com/maps/d/viewer?mid=1yMKNg31SYjDASoN-ZwH1jJoapFQ\&ll=10.10973362929658\%2C-20.126154816406256\&z=3. Acesso em 09/08/2017. 
corpo não é um fenômeno apenas natural, mas social, temporal e espacialmente construído.

Este texto analisa como travestis e transexuais femininas constroem suas percepções sobre a relação entre morte e espaço, vivendo sob a lógica da transnecropolítica instituída no Brasil (MBEMBE, 2003 e 2008). Participaram da investigação doze pessoas, sendo que seis se autoidentificaram como travestis e outras seis como transexuais femininas. As pessoas entrevistadas foram estimuladas pela leitura e visualização de imagens de seis notícias veiculadas por jornais on-line que divulgaram a morte de pessoas trans. Após a leitura das notícias elas desenvolveram suas narrativas com base em dois eixos investigativos. O primeiro, foi o relato de sua opinião a respeito da notícia veiculada. O segundo, sobre sua perspectiva em relação à própria morte. As narrativas foram analisadas a partir da metodologia de análise de conteúdo de Bardin (1977), que permitiu a construção de uma rede semântica de significados envolvendo a morte de pessoas trans.

O texto está estruturado em duas partes. Na primeira seção nós argumentamos que a população trans vitimada por assassinatos no Brasil possui formas específicas de interseção entre sexualidade e classe em que, ao desafiar a lógica do cálculo biopolítico, são considerados como seres supérfluos para a sociedade brasileira. Na segunda parte do texto são evidenciadas as formas de compreensão instituídas por travestis e transexuais sobre sua condição de precarização e exposição à morte.

\section{'DEUS ME PROTEJA, PORQUE EU VOU, MAS EU NÃO SEI SE EU VOLTO': ABANDONO E MORTE TRANS COMO POLÍTICA DE MANUTENÇÃO DA ORDEM}

A insegurança e a exposição à morte é um elemento cotidiano na vida de travestis e mulheres trans brasileiras, notadamente aquelas que sobrevivem da atividade comercial sexual. Azaleia relata essa percepção dizendo: "como eu morei em muitas casas, com muitas prostitutas, nós temos uma oração que fazemos antes de sair para trabalhar. 'Deus me proteja, porque eu vou, mas eu

não sei se eu volto’. Nós temos a fé, mas nós sabemos que estamos em constante 
perigo e tentamos não pensar nisso para viver.' (Entrevista realizada com Azaleia, 25/08/2013, em Curitiba).

A atividade de prostituição é a maneira como 90\% das travestis e mulheres trans sobrevivem economicamente no Brasil, conforme a Associação Nacional de Travestis e Transexuais (ANTRA). O território da prostituição é simultaneamente um lugar de vida e morte para o grupo. As travestis e mulheres transexuais relatam que o território da prostituição é o único espaço em que sua feminilidade é reconhecida e desejada7. Além disso, é por meio dele que elas desenvolvem amizades, redes de solidariedade e proteção (ORNAT, 2009). Contudo, a área de prostituição é também o espaço de maior vulnerabilidade ao homicídio. Azaleia diz que "o momento de trabalho, quando precisamos estar nas ruas, correndo atrás do nosso ganha pão, da nossa sobrevivência é o local mais crítico para sermos violentadas e assassinadas". (Entrevista realizada com Azaleia, em 25/08/2013, em Curitiba).

Conviver com a vulnerabilidade à morte é uma realidade com a qual pessoas trans têm que lidar de forma individualizada, já que não há políticas públicas específicas de proteção ao grupo no Brasil. As estatísticas de mortalidade e assassinatos têm sido produzidas por entidades e organizações não governamentais que fazem parte do movimento LGBTI e estão baseados nas reportagens de jornais veiculadas na internet como blogs, jornais e sites ${ }^{8}$.

A Secretaria de Direitos Humanos da Presidência da República possui um canal telefônico de denúncia e proteção de violação de direitos humanos de minorias (população em situação de rua, negra, com deficiência e LGBTI), chamado 'Disque 100'. Este projeto, inicialmente era mantido por organizações não governamentais e direcionado a combater o abuso contra crianças e adolescentes. Em 2003 o serviço foi institucionalizado, tornando-se responsabilidade do governo federal e em 2010 o leque de proteção foi ampliado

\footnotetext{
7 Outra contradição entre desejo e ódio foi apontado pelo levantamento do site pornô 'Red Tube' que mostra que os brasileiros são os mais interessados em procurar filmes protagonizados por mulheres trans e travestis. Ao mesmo tempo, é o país que mais mata travestis e trans no mundo. Fonte: https://goo.gl/LezGix. Acesso em 10/o8/2017.

8 Destaca-se a atuação do Grupo Gay da Bahia que desde o início da década de 1980 tem realizado estatísticas e sistematizações de assassinatos de pessoas LGBTI no Brasil por meio de notícias veiculadas na mídia nacional. Outra importante entidade de produção de dados de assassinatos da população trans no mundo é a Organização Não Governamental Transgender Europe.
} 
para outros grupos vulneráveis. Importante ressaltar que foi apenas em 2012 que houve a divulgação de dados oficiais sobre as violações de Direitos Humanos da população LGBTI, com base no referido canal de comunicação.

Nos dados baseados no 'Disque 100' a população trans aparece como um grupo invisibilizado em relação às denúncias de violência. Apenas 1,47\% do total das denúncias foram relativas a violências cometidas contra travestis e $0,49 \%$ contra pessoas transexuais (Brasil 2013, p.24). Os dados estatais apresentam fragilidades, indicando que os casos de violência e o número de mortes da população trans é ainda maior do que o contabilizado.

A ANTRA, em 2017 realizou um importante trabalho de contabilizar os assassinatos de travestis e transexuais no Brasil. Do total de 115 assassinatos registrados pela instituição no ano de 2017, entre os meses de janeiro a agosto, $5,21 \%$ foram de homens trans, $10,43 \%$ de mulheres trans e 84,34\% foram de travestis. O quadro dos registros de morte evidencia que a população trans vitimada por assassinatos apresenta diferenciações internas. Isso implica a necessidade de ampliar a compreensão de elementos que agregam diferentes níveis de vulnerabilidade à morte violenta da população trans no Brasil9.

As pessoas trans vitimadas por homicídios possuem uma média de vida de 27,9 anos de idade. Antunes (2013) aponta que a expectativa de vida da população trans no Brasil é de 35 anos e o coletivo Transrevolução ${ }^{10}$ apresenta a estimativa de 30 anos. Estas últimas estimativas de expectativas de vida trans consideram outros fatores além da violência letal, como a mortalidade por complicações do HIV e por procedimentos de transformação corporal sem adequado atendimendo médico.

As formas de matar a população trans variam. Abaixo de $2 \%$ ocorreram assassinatos por apedrejamento $(1,7 \%)$, atropelamento $(1,7 \%)$, estrangulamento $(1,7 \%)$, pauladas $(1,7 \%)$, queimação (0,9\%) e asfixia (0,9\%). Os demais casos $(1,7 \%)$ não apresentam informações. Foram verificados que $51,3 \%$ dos

9 Importante destacar que as notícias de assassinatos trans reportados pela mídia, fontes da ANTRA, podem apresentar distorções sobre as identidades das pessoas que foram mortas. As reportagens não trazem a autoidentificação das vítimas como mulheres transexuais ou travestis. A categorização é realizada de modo arbitrário, pelo conhecimento do senso comum que a sociedade faz dos seus corpos.

10 Dado extraído de: http://blogs.odia.ig.com.br/lgbt/2015/01/29/dia-nacional-davisibilidade-trans-e-celebrado-com-manifestacao-na-cinelandia-nesta-quinta-feira/. Acesso em 10 de agosto de 2017. 
assassinatos foram resultantes de tiros, $18,3 \%$ de facadas, $12,2 \%$ de espancamentos, sendo que em $7,8 \%$ dos assassinatos há mais do que uma forma empregada para matar, envolvendo requintes de crueldade, tortura e espetacularização do suplício das vítimas.

Cabral, Silva e Ornat (2013) apontam que o espaço é de fundamental importância para a escolha da forma de matar pelos assassinos. Em locais onde há um maior fluxo de pessoas a execução da vítima é rápida, com a utilização de armas de fogo. No entanto, quando o assassino consegue estar em locais de menor fluxo ou ausência de pessoas, a vítima é executada com apurada barbárie, embebida de violência psicológica e tortura física. Nestas condições, as principais vítimas são travestis que têm o corpo mutilado, com introdução de objetos no ânus, arrastado pelas ruas, alvejado por tiros e arremessado de viadutos.

O grupo marcado para morrer é composto por travestis jovens, pobres e, majoritariamente, dependentes do trabalho sexual. É a interseccionalidade (CRENSHAW, 1991; COLLINS, 1998; MCCALL, 2005; DAVIS, 2009) desses elementos que constituem os corpos passíveis de serem mortos, evidenciando, como Puar (2007), que há formas particulares de hierarquização social das vidas que importam socialmente, mesmo dentro da já estigmatizada população LGBTI. Os corpos de travestis jovens são objetos políticos, por excelência, pois "o corpo implica mortalidade, vulnerabilidade, agência: a pele e a carne nos expõe ao olhar de outros, mas também ao toque e à violência e os corpos nos coloca em risco de tornar também agência e instrumento disso tudo" (BUTLER, 2004, p. 26 - tradução livre) ${ }^{11}$.

São pessoas cujos corpos são alvo de intervenção disciplinar, tal qual aponta Foucault (1978), que se inicia com a mais tenra idade e se viabiliza espacialmente pela vivência cotidiana da gender tyranny (DOAN, 2010). As travestis e transexuais enfrentam rejeição em suas casas e também nas escolas, comprometendo as chances de obter melhores oportunidades de trabalho e renda quando adultas (BOULEVARD, 2013; LEE, 2013; NIKARATTY, 2013). A

11 "the body implies mortality, vulnerability, agency: the skin and the flesh expose us to the gaze of others, but also to touch, and to violence, and the bodies put us at risk to becoming agency and instrument of all these as well". 
ANTRA afirma que $57 \%$ da população trans não concluiu nem mesmo o ensino fundamental e apenas $0,02 \%$ conseguiram, apenas recentemente, entrar em cursos superiores ${ }^{12}$.

São forças estruturais que paulatinamente constroem a jornada da 'slow death' (BERLANT, 2007), prematura e violenta de travestis e mulheres transexuais. O fim da jornada culmina no seu extermínio de formas brutais, pois, conforme Foucault (1995) o suplício faz parte do ritual social de punição. O martírio deve ser ostentoso, a fim de servir de exemplo para ordem social, tornando infame a própria vítima e além da agressão letal, deve haver práticas simbólicas de humilhação.

A existência material de pessoas pobres, não conformadas ao gênero atribuído ao nascimento é uma rebeldia contra o aparelho biopolítico no Brasil (FOUCAULT, 1997). A vida de travestis e mulheres transexuais se faz de um conjunto de relações entre estruturas macropolíticas de poder e de técnicas micropolíticas através das quais seus corpos são imbricados com nações, estados e capitais (STRYKER, CURRAH, AND MOORE, 2008). Suas vidas são consideradas inviáveis, constituindo sujeitos que vivem uma fronteira tênue entre a vida e a morte (FOUCAULT, 1997).

O estabelecimento das fronteiras entre aqueles que têm a vida assegurada e àqueles que são direcionados à morte está baseado em sistemas hierárquicos de valores em torno das diferenças econômicas, culturais e sociais que são constituídos discursivamente como naturais. Tal sistema de hierarquização tem constituído as vidas de travestis e mulheres transexuais como algo depreciativo, como seres indesejáveis socialmente (STRYKER, 2014).

As mortes das travestis e mulheres transexuais se inscrevem em uma lógica ordenada de representação do poder e na forma como seus corpos e vidas são compreendidas como dispensáveis socialmente. O vínculo entre a vida e a

12 A ANTRA afirma que a entrada e manutenção de travestis e transexuais nas instituições de ensino foram facilitadas pela conquista do direito ao uso do 'nome social', regulamentado em nível federal pelo Decreto n. 8727 de 28 de abril de 2016, embora vários estados brasileiros haviam antecipado e possibilidade de uso de nome social em instituições de ensino e saúde. $\mathrm{O}$ nome social é aquele correspondente à identidade de gênero, mas que não substitui o 'nome civil'. O nome civil é o nome utilizado nos documentos e são correspondentes ao sexo designado no nascimento. A mudança dos registros civis só ocorre no Brasil por meio de processo e autorização judicial. 
morte das travestis só são compreendidas por meio das políticas sociais e econômicas que operam as mortes trans (AGAMBEN, 1998).

A vida e a morte são questões políticas, cuja gestão depende das relações de poder e da valorização hierarquizada de vidas que devem ser preservadas ou desperdiçadas. A morte das travestis, portanto, se coloca como argumenta Agamben (1998) e Mbembe (2003), como um trabalho, uma prática, uma tarefa do poder que distribui a morte desigualmente, atingindo as vidas classificadas como dispensáveis.

\section{'MENOS UMA PARA INCOMODAR': NARRATIVAS TRANSNECROPOLÍTICAS}

As narrativas desenvolvidas pelas pessoas que participaram da pesquisa foram sistematizadas por meio de análise de conteúdo que permitiu a organização de uma rede semântica composta por três comunidades discursivas distintas. A primeira comunidade gira em torno da categoria interseccionalidade, evidenciando o reconhecimento do grupo de diferentes níveis de vulnerabilidade ao homicídio entre as pessoas trans. A segunda comunidade revela sua compreensão em torno dos processos sociais e econômicos que constituem as trajetórias de morte de travestis e mulheres transexuais. A terceira comunidade discursiva verificada é a conscientização da criação do inimigo social e a consequente banalização da morte de travestis e mulheres transexuais em espaços de prostituição.

Os discursos de travestis e mulheres transexuais evidenciam pleno reconhecimento de haver condições específicas que sustentam regimes desiguais de viver e morrer, havendo interseções específicas entre pobreza, gênero e sexualidades (HARITAWORN; KUNTSMAN; POSOCCO, 2014). O trecho de depoimento de Rosa é exemplar no sentido de argumentar haver entre a população trans aquelas pessoas que estão mais vulneráveis a assassinatos:

eu vejo que tem pessoas que tem maior probabilidade de ser morta, porque está num nível de risco maior que são as travestis, profissionais do sexo. Eu, por exemplo, mesmo sendo uma mulher trans eu sofro menos preconceito do que quem está na rua, exposta lá de madrugada. Eu agora consegui trabalhar aqui na ONG e isso me ajuda sair do risco de morte. Somos trans iguais, mas as travestis estão mais expostas à serem 
assassinadas do que eu que agora estou em outra ocupação. (Entrevista realizada com Rosa em 07/09/2013, em Curitiba)

As entrevistadas argumentam que há uma hierarquização social entre travestis e mulheres transexuais em relação a possibilidade de conseguir sustento econômico fora da prostituição, o que minimiza o risco de serem assassinadas. As travestis e mulheres trans que não realizam a cirurgia de redesignação de $\operatorname{sexo}^{13}$ são mais vulneráveis ao homicídio. A adequação dos corpos às normas de gênero cria, segundo elas, maior probabilidade de conseguir outras formas de sobrevivência para além da prostituição, diminuindo os riscos de ser assassinada.

As narrativas evidenciam haver a constituição de uma transnormatividade ${ }^{14}$ que separa as pessoas trans em dois tipos (JOHNSON, 2016; LEBLANC, 2010; MCDONALD, 2006). As mulheres transexuais respeitáveis, aquelas que corrigem sua genitália para se adaptar às normas de gênero pois nasceram em um ‘corpo errado' e as 'outras' transgressoras. Aquelas que mantém a 'hot mess' são as mais vulneráveis à serem mortas, majoritariamente travestis.

A segunda comunidade discursiva que faz parte da rede semântica resultante das narrativas das pessoas trans entrevistadas, revela 0 reconhecimento dos processos sociais e econômicos que instituem sua morte civil e questionam as razões da criação da necropolítica em torno de suas vidas. O depoimento de Margarida é exemplar dessa visão política:

eu não sei quanto vale a vida de uma trans. Sei que no Brasil vivemos a violência familiar e também a violência institucional. Eu sofri todas. Desde o primeiro momento que você se assume você aprende que você está errada, que você não presta, que você é doente. Sua família repete 'você tem algum distúrbio'. Se você ouve isso do seu pai e da sua mãe, quem vai dizer ao contrário para você? Que você vale a pena. Todo mundo prega essa mesma coisa. Depois da família é a escola, a igreja e tudo mais. Não somos reconhecidas, não temos direito a nome, saúde e família (...). Ninguém pergunta porque você veio parar na situação de prostituição e pensam que a culpa é sua quando te

13 Em 2018 a Organização Mundial de Saúde (OMS) retirou a transexualidade do Código Internacional de Doenças (CID) e o Brasil deve se adaptar à nova legislação, mas ainda não houve regulamentação nacional sobre o tema até o momento.

14 A ideia de transnormatividade é utilizada nesse capítulo como sendo a adoção de agendas e práticas normativas e políticas conservadoras por pessoas trans que acaba por criar hierarquias identitárias dentro das comunidades trans. 
matam. Eles dizem 'que bom, menos uma para incomodar' a sociedade. Porque você é marginal, bandida, perigosa. (...) Eu não entendo porque as pessoas se assustam quando vêm as travestis e transexuais tentando estudar. Não entendo porque isso é negado. Não entendo quanto vale nossa vida, mas eu sou um ser humano e eu luto para as pessoas me verem assim, como ser humano. (Entrevista realizada com Margarida, em 15/09/2013, em Curitiba).

As narrativas evidenciam que as travestis e transexuais femininas resistem e denunciam o abandono sofrido durante sua existência, são conscientes e lutam contra o processo de sua desumanização. Elas reconhecem a necropolítica que cria a possibilidade de destruição de suas vidas, simplesmente porque elas são consideradas como vidas dispensáveis, mortes não lamentadas socialmente (AGAMBEN, 1998 E MBEMBE, 2003).

A terceira comunidade discursiva da rede semântica evidencia como elas compreendem a forma como a sociedade brasileira cria discursivamente a ideia do 'inimigo', aquele que deve ser destruído, para que aqueles seres que realmente importam possam viver. A imagem de travestis e transexuais femininas descrita por Iris evidencia o reconhecimento desse processo, descrevendo sua imagem social: "a travesti é vista como aberração, monstro e automaticamente as pessoas não gostam de se aproximar porque se sentem com medo da gente. Porque a gente é vista como drogada, bandida, a boca do lixo". (Entrevista realizada com Iris, em 17/08/2013, em Ponta Grossa).

A transnecropolítica é praticada cotidianamente para demarcar as vidas que são consideradas boas e as que são ruins (BUTLER, 2004). O cálculo necropolítico visa proteger as vidas normativas enquanto sacrifica as vidas trans (HUTTA, 2013). A morte física de um grupo já morto socialmente é o desfecho previsível pelas narrativas trans, como pode ser visto a seguir:

A exclusão em vida eu acho que é a pior de todas as coisas. Mas existe uma higienização da sociedade. Para a sociedade é extremamente normal ver uma travesti morta. Essa é uma imagem comum. A violência, a morte violenta e cruel está sempre ligada àquilo que a sociedade pensa da gente. O estigma da prostituição, da promiscuidade. Eu acho que é por isso tanta violência. (...) então eu acredito que a sociedade aplaude as mortes. Você pode colocar isso aí na sua pesquisa. Eu digo: a sociedade aplaude a violência contra travestis e transexuais. Eu quero que você dê ênfase nisso que eu estou te falando. Porque é a realidade. (...) a sociedade aplaude sim que outras pessoas 
façam o serviço sujo que elas gostariam que fosse realizado, que é o extermínio de nós, travestis e transexuais. (Entrevista realizada com Margarida, em 15/09/2013, em Curitiba. )

O relato de Margarida evidencia o reconhecimento do grupo de que há várias formas de 'fazer morrer' ou ainda de 'deixar morrer' ou 'expor determinadas pessoas à morte' pela criação de situações de negligência estrutural em relação às travestis e transexuais femininas. A sociedade brasileira cria e alimenta governanças específicas de poder que distribuem diferencialmente a violência, a morte e os variados níveis de precarização da vida da população trans (BUTLER, 2004).

A presença constante da perspectiva de morte vivenciada pelas travestis e mulheres trans brasileiras constitui um estilo de vida imediatista. Poucos planos de vida a longo prazo são realizados, o que agrava, ainda mais, sua vulnerabilidade. Elas acabam negligenciando cuidados de si, de saúde, aposentadoria e se arriscam em situações de perigo, já que não se projetam no futuro. Rosa diz:

eu não penso e nem me imagino envelhecendo. Talvez, justamente porque eu acho que não vou chegar lá. Então, eu vivo intensamente cada dia, porque a velhice nem vai chegar. (...) Parece que as travestis e transexuais são determinadas a não chegar a terceira idade.(Entrevista realizada com Rosa em 07/09/2013, em Curitiba).

A transnecropolítica é operada espacialmente por meio da criação de fronteiras onde o 'inimigo' pode ou não circular na cidade. As narrativas apontam para vários espaços de exclusão e o reconhecimento de que as áreas de prostituição são os espaços que possibilitam simultaneamente a vida e a morte das travestis e transexuais. O mesmo espaço da prostituição que lhe possibilita o sustento econômico, e portanto a vida, é também o espaço de maior vulnerabilidade à violência e morte. Esta simultaneidade de significados opostos 'vida e morte' se faz a partir de uma politica espacial deliberada que viabiliza a transnecropolítica, como relata Azaléia:

a mesma sociedade hipócrita que te condena e mata, é a que te sustenta na prostituição. A rua é o local de maior vulnerabilidade, porque você sai com alguém que não conhece e nunca sabe se voltará, porque a pessoa pode ser boa, mas também pode ser ruim. Na prostituição rola muita disputa de 
poder, dinheiro e drogas, o que faz com que a vulnerabilidade a sofrer violência e morte seja maior, eu acho (Entrevista realizada com Azaleia, em 25/08/2013, em Curitiba).

A transnecropolítica não acaba com a morte física, mas é mantida por um cuidadoso trabalho de extermínio da memória da existência daquele que construído discursivamente como o 'inimigo'. As narrativas de travestis e transexuais sobre a morte sofrida traz a construção da invisibilidade de sua existência feminina. Jasmim cria uma narrativa em torno do ocultamento da existência trans, mesmo depois da morte física trágica apresentada de forma cruel nos jornais ${ }^{15}$ :

Nós morremos como homem. Se você reparar, nós não aparecemos nem nas estatísticas como travestis, mas como homens. Nem o governo reconhece a nossa existência. Veja as notícias de assassinatos. Aparece assim, 'o' travesti, no masculino, foi 'morto'. Nossa transição e a condição feminina não é respeitada. Agora veja, eu tenho um sobrinho. Sempre peço para ele falar 'a' travesti. Mas daí ele lê um jornal e vê 'o' travesti e aprende dessa forma, entende? (Entrevista realizada com Jasmim, em 27/o8/2013, em Curitiba).

A negação da feminilidade pela família, notadamente na hora do enterro, é um elemento importante na narrativa sobre a construção do ‘inimigo' social. O luto familiar pela morte de travestis e transexuais é relatado por elas com ressentimentos, já que a família, muitas vezes, não respeita a feminilidade, mesmo depois de mortas. Os trâmites burocráticos que envolvem a morte são realizados pelo nome masculino, o que é considerado uma afronta pela sua luta em vida pelo respeito à sua feminilidade, como relata Violeta:

Nenhuma quer ser enterrada como homem. Tenho uma amiga que deixou até a roupa dela preparada para quando morresse, coitada. Parecia que sabia o que ia acontecer com ela, foi morta. Isso é o cúmulo, você ter medo até depois que a gente está morta, nem assim temos paz. Quando acontece da ONG preparar o velório e o enterro, tudo é feito com o nome social feminino. Tem até um túmulo da ONG que tem umas vinte meninas enterradas que a família não procurou o corpo. Mas quando é a família, eles acabam fazendo com o nome de homem e se você pegar o registro de óbito, vai estar lá, homem. Então nossa existência se apaga. (Entrevista realizada com Violeta, em 19/09/2013, em Curitiba).

15 Os jornais expõem fotos de pessoas trans assassinadas mostrando os corpos feridos e dilacerados, sem preservar o respeito pela vítima e as pessoas que a estimam. 
A transnecropolítica se efetiva na sociedade brasileira em um trabalho ordenado cotidianamente para criar as vidas que são consideradas importantes e aquelas que são descartáveis, como são consideradas as travestis e mulheres trans. A lógica política, social e econômica que opera a gestão da vida e morte dessas pessoas baseia-se na sua exclusão em vida, no extermínio do seu corpo e no ocultamento de sua existência após suas mortes.

\section{CONSIDERAÇÕES FINAIS}

Durante a escrita desse texto foi necessário atualizar os dados estatísticos sobre assassinatos de travestis e transexuais, pois a cada 48 horas uma vida trans é descartada violentamente no Brasil. Embora o ativismo trans brasileiro seja atuante e esteja monitorando e denunciando a dinâmica de homicídios, as estatísticas se mantém elevadas.

$\mathrm{O}$ texto argumentou que essas mortes prematuras e violentas sofridas pela população trans faz parte de uma meticulosa engrenagem, de uma governança específica que tem como alvo travestis e transexuais femininas, jovens, pobres e dependentes do trabalho sexual. A perspectiva interseccional do grupo vitimado permitiu evidenciar uma crescente transnormatividade que vem marcando as experiências da comunidade trans no Brasil.

As narrativas das pessoas que colaboraram com este capítulo evidenciam que o grupo reconhece as dinâmicas de poder que criam sua a vulnerabilidade ao homicídio. A criação e alimentação da imagem de travestis e transexuais femininas como os inimigos contra os quais é preciso lutar, torna suas vidas descartáveis e suas mortes comemoradas.

A transnecropolítica é operada espacialmente por processos constantes de exclusão que culmina com o extermínio do corpo e o ocultamento de sua existência após a morte. $\mathrm{O}$ entendimento das mortes trans no Brasil como um processo político pode construir um caminho de desconstrução de suas vidas como vidas descartáveis. O grito de guerra que abre esse texto 'quando uma trans é morta, outras mil se levantam', necessita ser ampliado para o conjunto da sociedade brasileira que precisa gritar: 'quando uma trans é morta, todos nós nos levantamos'! 


\section{REFERÊNCIAS}

AGAMBEN, Giorgio. Homo Sacer: Sovereign Power and Bare Life. Stanford: Stanford University Press, 1998.

ANTUNES, Pedro Paulo Sammarco. Travestis envelhecem? São Paulo: Annablume, 2013.

BALZER, Carsten (Carla La Gata); HUTTA, Jan Simon; ADRIÁN, Tamara; HYLDAL, Peter and STRYKER, Susan. Transrespect versus transphobia worlwide. A comparative review of the Human Rights Situation of gendervariant / Trans People. Berlin: Transgender Europe (TGEU), 2012.

BARDIN, Laurence. Análise de Conteúdo. Lisboa: Edições 70, 1977.

BERLANT, Lauren. Slow Death (Sovereignty, Obesity, Lateral Agency). Critical Inquiry 33 (4): 754-80, 2007.

BOULEVARD, Gláucia. "Vida de travesti é luta! Luta contra a morte, luta contra o preconceito, luta pela sobrevivência e luta por espaço". In Geografias

malditas: corpos, sexualidades e espaços, edited by Joseli Maria Silva, Marcio Jose Ornat and Alides Baptista Chimin Junior, 69 - 81, Ponta Grossa: Todapalavra, 2013.

BRASIL. Relatório sobre Violência Homofóbica no Brasil: ano de 2012. Brasília: Secretaria de Direitos Humanos da Presidência da República, 2013.

BUTLER, Judith. Bodies that matter: on the discursive limits of "sex". London: Routledge, 1993.

BUTLER, Judith. Precarious life: the powers of mourning and violence. London, New York: Verso, 2004.

CABRAL, Vinícius; SILVA, Joseli Maria; ORNAT, Marcio Jose. "Espaço e morte nas representações sociais de travestis.” In Geografias malditas: corpos, sexualidades e espaços, edited by Joseli Maria Silva, Marcio Jose Ornat and Alides Baptista Chimin Junior, 246 - 275, Ponta Grossa: Todapalavra, 2013.

COLLINS, Patricia Hill. Black feminist thought: knowledge, consciousness, and the politics of empowerment. New Yourk, Routledge, 2000.

CRENSHAW, Kimberlé Williams. Mapping the margins: intersectionality, identity politics, and violence against women of color. Stanford Law Review 43(6): 1241 - 1299, 1991.

DAVIS, Kathy. Intersectionality as Buzzword: A Sociology of Science Perspective on What Makes a Feminist Theory Successful, Feminist Theory 9(1): 67-85, 2009 . 
DOAN, Petra L. The tyranny of gendered spaces - reflections from beyond the gender dichotomy. Gender, Place \& Culture: A Journal of Feminist Geography, 17(5), $635-654,2010$.

FOUCAULT, Michel. History of sexuality, vol. 1. New York: Vintage, 1978.

FOUCAULT, Michel. Discipline and Punish: The birth of the prision. New York: Vintage Books, 1995.

FOUCAULT, Michel. Society Must Be Defended: Lectures at the Collège de France, 1975-1976. New York: St. Martin's, 1997.

Grupo Gay da Bahia. Assassinato de homossexuais no Brasil. Relatório anual do Grupo Gay da Bahia.

http://www.ggb.org.br/assassinatos\%20de\%2ohomossexuais\%20no\%2obrasil \%202011\%20GGB.html (acessed march 12, 2017), 2014.

HARITAWORN, Jin; KUNTSMAN, Adi and POSOCCO, Silvia. Queer Necropolitics. Abingdon: Routledge, 2014.

HUTTA, Jan Simon. Queer necropolitics and other power geometries in Brazil. Geographies of Sexualities Conference in Lisbon, September (Session Presentation), 2013.

JOHNSON, Austin H. Sociological Inquiry, 86(4): 465 - 491, 2016.

LEBLANC, Fred Joseph. Unqueering Transgender? A queer geography os transnormativity in two on line communities. Master thesis - Gender \& Women's Studies. Victoria University of Wellington. Wellington. p. 143, 2010.

LEE, Debora. "A geografia de uma travesti é uma barra, é matar um leão a cada dia”. In Geografias malditas: corpos, sexualidades e espaços, edited by Joseli Maria Silva, Marcio Jose Ornat and Alides Baptista Chimin Junior, 27 - 38, Ponta Grossa: Todapalavra, 2013.

MADDRELL, Avril and SIDAWAY, James D. Deathscapes: spaces for death, dying, mourning and remembrance. Farnham: Ashgate Publishing Limited, 2010.

MBEMBE, Achille. Necropolitics. Public Culture 15(1): 11 - 40, 2003.

MBEMBE, Achille. "Necropolitics." In Foucault in an Age of Terror. Essays of biopolitics and defense of society, edited by Stephen Morton and Stephen Bygrave, 152 - 182, New York: Palgrave, 2008.

MCCALL, Leslie. The Complexity of Intersectionality. Signs: Journal of Women, Culture and Society, 30(3): 1771 - 1800, 2005.

MCDONALD, Myfanwy. An Other Space. Journal of Lesbian Studies 10(1-2), $201-214,2006$. 
NIKARATTY, Leandra. "O que mais me marcou na vida é ser barrada e não poder entrar nos lugares: esta é a geografia de uma travesti”. In Geografias malditas: corpos, sexualidades e espaços, edited by Joseli Maria Silva, Marcio Jose Ornat and Alides Baptista Chimin Junior, 239 - 54, Ponta Grossa: Todapalavra, 2013.

ORNAT, Marcio Jose. Espacialidades travestis e a instituição dos territórios paradoxais. In Geografias Subversivas: discursos sobre espaço, gênero e sexualidades, edited by Joseli Maria Silva, 177 - 210, Ponta Grossa:

Todapalavra, 2009.

PUAR, Jasbir. Terrorist Assemblages: Homonationalism in Queer Times, Durham, NC: Duke University Press, 2007.

SILVA, Joseli Maria; ORNAT, Marcio Jose. Transfeminism and Decolonial Thought: The Contribution of Brazilian Travestis. TSQ: Transgender Studies Quarterly 3(1-2): 220 - 227, 2016

STRYKER, Susan. Biopolitics. TSQ: Transgender Studies Quarterly 1(1-2): 38 42, 2014.

STRYKER, Susan, PAISLEY Currah, and MOORE, Lisa Jean. Introduction: Trans-, Trans, or Transgender. WSQ 36(3-4): 11 - 22, 2008.

Recebido em agosto de 2019 Aceito em outubro de 2019 